\title{
Effects of drying conditions on the content of glycosides and antioxidants of packed bed of stevia leaves
}

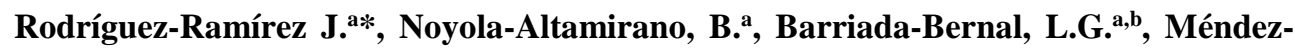 \\ Lagunas L.L. a \\ ${ }^{a}$ Instituto Politécnico Nacional CIIDIR Oaxaca, Hornos 1003 Sta. Cruz Xoxocotlán, Oaxaca 71230, \\ México. \\ b Consejo Nacional de Ciencia y Tecnología, Hornos 1003 Sta. Cruz Xoxocotlán, Oaxaca 71230, \\ México.
}

*E-mail of the corresponding author: jrodrigr@ipn.mx

\begin{abstract}
The commercial value of stevia dehydrated leaves is related to the content of glycocides and their appearance. The present work approaches the effect of packed bed drying conditions (temperature, flow rate and solid loading) on glycosides and antioxidants activity of stevia leaves of Morita II variety. Diffusion coefficient was calculated. The drying times ranged between 34 and 160 minutes, the temperature was the most significant factor followed by solid loading and flow rate. Drying increases the concentration of antioxidants, stevioside and reduces rebaudioside A.
\end{abstract}

Keywords: drying, packed bed, stevia rebaudiana, glycosides, antioxidants 
Effects of drying conditions on the content of glycosides and antioxidants of packed bed of Stevia leaves

\section{Introduction}

Stevia leaves are a source of bioactive compounds, among which are steviol glycosides that confer a high sweetening capacity and antioxidant compounds such as phenols and flavonoids, which has a therapeutic value ${ }^{[1]}$. The commercial value of stevia dehydrated leaves is related to the content of glycosides and their appearance. Some drying methods has been applied on stevia leaves, among shade drying, convective drying with longitudinal-flow at low $\left(30\right.$ and $\left.80^{\circ} \mathrm{C}\right)$ and high temperatura $\left(100\right.$ and $\left.180^{\circ} \mathrm{C}\right)$ and liophylization ${ }^{[2,3,4]}$. In the traditional process, fresh leaves are spread on a mesh or perforated plate in thin or thick layer and warm air is forced through the layer leaves to remove the moisture. The drying time could be reduced by fluidizing the leaves, but the quality of the final product may decrease. This research aimed to evaluate the effect of the drying conditions (temperature, flow rate and solid loading) of packed bed (PB) of stevia leaves Morita II variety on glycosides and antioxidants content.

\section{Materials and Methods}

\subsection{Raw material}

Fresh leaves of S. rebaudiana variety Morita II were collected from an organic crop in Oaxaca, Mexico (latitude: 16 $19^{\circ}$, longitude: $98^{\circ} 23^{\prime}$ ). Fresh leaves with no mechanical damage, no apparent evidence of fungi or bacteria harm and uniform color were selected.

The dimensions, density, and moisture content of the fresh leaves were measured. The void fraction of the bed was calculated by dividing the density of the bed between the density of the leaves. The thickness was measured with a micrometer. The area of the leaves was measured with image analysis using the Image ${ }^{\circledR}$ version 1.50 i program. The density of the leaves was determined using the buoyant force method (YDK 01S kit, Denver Instrument).

The moisture content was determined by the method 934.01 of the AOAC. ${ }^{[5]}$.

\subsection{Fixed Bed Drying}

The samples were dehydrated in a lab scale fluidized bed dryer with a glass fluidization tube with a height of $50 \mathrm{~cm}$, a diameter of $10 \mathrm{~cm}$ and a thick of $0.2 \mathrm{~cm}$. The packed bed drying process was carried out introducing the load of leaves in a perforated plastic basket. The dried air is heated with an electric resistance of $1 \mathrm{~kW}$ and the temperature is regulated by a PID controller (Love control, 32DZ). The air flow is regulated with an adjustable AC drive controller using a asynchronous motors (Altivar ${ }^{\mathrm{TM}} 16$ Telemecanique). The drying kinetics were obtained by weighing the fluidization tube and the loading of the stevia leaves in a precision balance (Sartorius ED4202S-CW), considering time intervals determined by the drying conditions (2, 3 or $5 \mathrm{~min}$ ). The drying was finished when the weight does not change in three consecutive measurements. The effective diffusion coefficient was calculated using 
the analytical solution of the Fick equation considering only the first term of the serie and employing experimental data $\left(\operatorname{Ln}\left(\mathrm{X}-\mathrm{X}_{\mathrm{f}} / \mathrm{Xo}-\mathrm{X}_{\mathrm{f}}\right)\right.$ vs time), with lineal tendence and a coefficient correlation $>0.995$.

\subsection{Antioxidant compounds.}

The measurement of antioxidant capacity $\left(\mathbf{C}_{\mathbf{A}}\right)$, total phenolic content $\left(\mathbf{F}_{\mathbf{T}}\right)$ and total flavonoid content $\left(\mathbf{F}_{\mathbf{L}}\right)$, were determined using the 2,2-diphenyl-1-picrylhydrazyl free radical scavenging activity, the Folin-Ciocalteu method and the aluminum chloride colorimetric method respectively, as detailed by Méndez-Lagunas et al. ${ }^{[6]}$. All the chemical products were purchased in Sigma-Aldrich.

\subsection{Steviol glycosides compounds.}

\subsubsection{Chemicals and reagents}

Acetonitrile and water (HPLC grade, Sigma Aldrich, USA) were used for the mobile phase preparation. Standard of stevioside and rebaudioside A were purchase in Sigma Aldrich.

\subsubsection{Sample preparation}

Fresh $(0.4 \mathrm{~g})$ or dry $(0.1 \mathrm{~g})$ ground leaves were mixed $5 \mathrm{~mL}$ de agua. The mixture was sonicated at $44 \mathrm{KHz}$ for 20 minutes at room temperature and centrifuged at $2080 \mathrm{rpm}$ for 5 min. The supernatant was separated from the precipitate. Two consecutive extractions were made to the precipitate. The accumulated volume of the supernatant was measured and stored in amber vials. An aliquot $(20 \mu \mathrm{l})$ of the accumulated of the three supernadant consecutives extractions was used for the quantification of stevioside $\left(E_{V}\right)$ and rebaudioside $A\left(R_{A}\right)$.

\subsubsection{HPLC analysis}

An isocratic HPLC method was performed for the determination of steviol glycosides using an ODS Hypersil C18 column $(250 \times 4.6 \mathrm{~mm}$, particle size $5 \mu \mathrm{m})$ and a UV detector set at $210 \mathrm{~nm}$. The mobile phase consisted of acetonitrile-water (35:65, v/v) at a flow rate of 1 $\mathrm{ml} / \mathrm{min}$. Data analysis was carried out using Chromera software. Calibration curves of stevioside and rebaudioside A were constructed over the range $0.03-0.9 \mathrm{mg} / \mathrm{ml}$. In order to compare the effect of the drying conditions on the $R_{A}$ and $E_{V}$ concentrations, the units of measure were expressed on the basis of dry matter $\left(\mathrm{mg} / \mathrm{g}_{\mathrm{dm}}\right)$.

\subsection{Experimental design and statistical analysis}

The drying tests were carried out following a 3x2x2 complete factorial experimental design with 3 replicas. The factors studied were temperature, T (40, 50 and $\left.60{ }^{\circ} \mathrm{C}\right)$, air flow, $\overline{\mathrm{u}},(2$ and $3.5 \mathrm{~m} / \mathrm{s})$ and area solid loading, $\rho_{\mathrm{A}}\left(1.5\right.$ and $\left.3 \mathrm{~kg} / \mathrm{m}^{2}\right)$. 
Effects of drying conditions on the content of glycosides and antioxidants of packed bed of Stevia leaves

All the chemical analysis was performed on triplicates. The analysis of variance (ANOVA) was used to evaluate the effect of operating conditions on the drying time, the concentration of antioxidants (antioxidant capacity, total phenols and flavonoids) and the concentration of glycosides (stevioside and rebaudioside A). The software NCSS version 9 was used to perform the statistical analysis.

\section{Results and Discussions}

3.1. Physical characteristics. Fresh stevia leaves had a moisture content (Xo) of $0.75 \pm 0.03$ $\mathrm{kg}_{\mathrm{w}} / \mathrm{kg}_{\mathrm{wm}}$, a thickness of $2.08 \pm 0.1 \mathrm{~mm}$, a maximum equivalent diameter of $6.53 \mathrm{~cm}$ and a minimum of $2.53 \mathrm{~cm}$. The density of the leaves was $0.95 \pm 0.031 \mathrm{~g} / \mathrm{cm}^{3}$. The packed bed of $1.5 \mathrm{~kg} / \mathrm{m}^{2}$ solid loading had a bed height of $3.2 \mathrm{~cm}$, a bulk density of $60 \mathrm{~kg} / \mathrm{m}^{3}$ and a void fraction of 0.93 , while the bed of $3.0 \mathrm{~kg} / \mathrm{m}^{2}$ had a height of $5.2 \mathrm{~cm}$, a bulk density of $80 \mathrm{~kg} / \mathrm{m}^{3}$ and a void fraction of 0.92 .

3.2. Drying kinetics. Figures 1 show drying curves of packed bed of stevia leaves. The curves are grouped depending on the drying temperature, the air flow and the packing. The drying rate increases with the increase in temperature and air velocity, as well as with the decrease of solid loading. At low air flow the packaging has a greater effect on the drying rate. The drying rate curves have a second-order polynomial tendency.

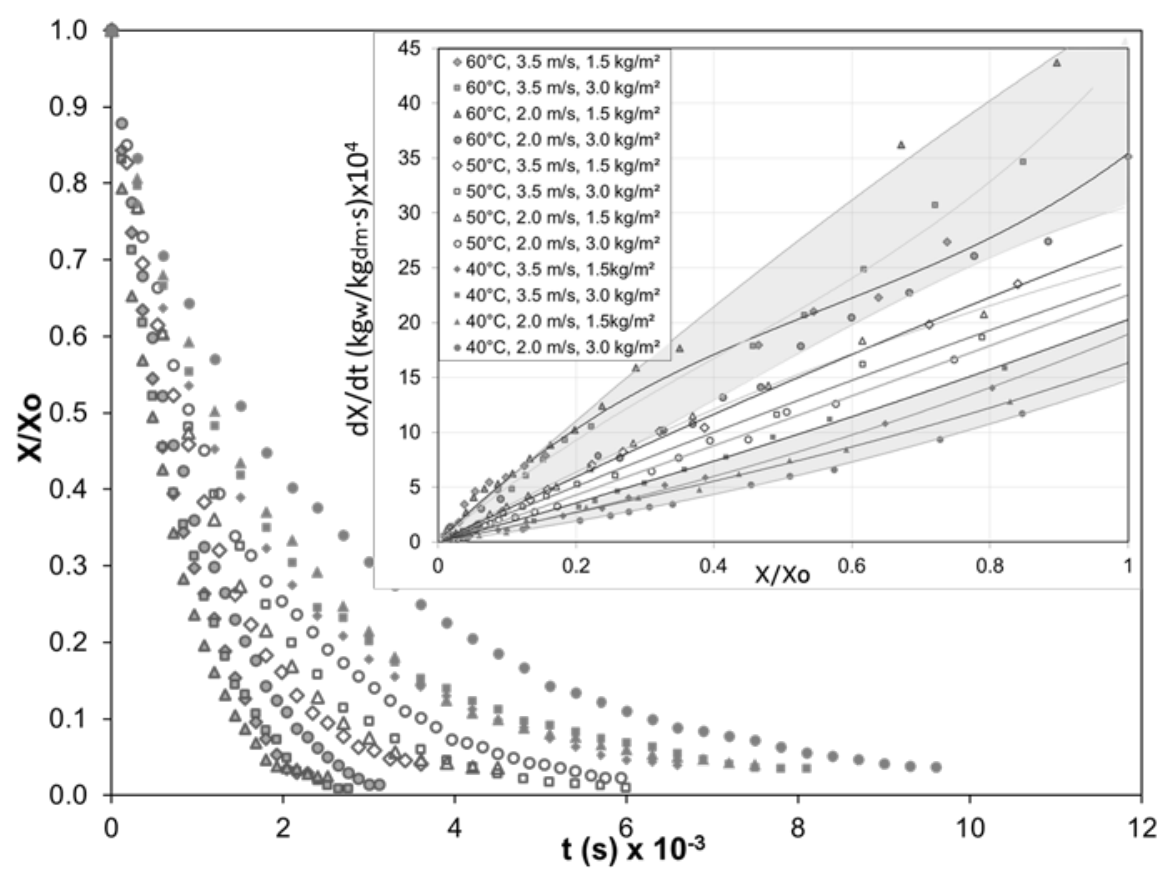

Fig. 1 Drying curves of leaves of stevia in packed bed. 
Table 1. Effective diffusivity in stevia leaves and drying time of packed bed of leaves.

\begin{tabular}{ccccc}
\hline $\mathrm{T}$ & $\overline{\mathrm{u}}$ & $\rho_{\mathrm{A}}$ & $\begin{array}{c}\mathrm{t} \\
(\mathrm{min})\end{array}$ & $\begin{array}{c}\mathrm{D}_{\text {eff }} * 10^{10} \\
\left(\mathrm{~m}^{2} / \mathrm{s}\right)\end{array}$ \\
\hline 40 & $(\mathrm{~m} / \mathrm{s})$ & $\left(\mathrm{kg} / \mathrm{m}^{2}\right)$ & & \\
40 & & & & 6.73 \\
40 & 2.0 & 3.0 & 160 & 9.31 \\
40 & 2.0 & 1.5 & 130 & 9.74 \\
50 & 3.5 & 3.0 & 135 & 10.65 \\
50 & 3.5 & 1.5 & 124 & 11.61 \\
50 & 2.0 & 3.0 & 87 & 16.18 \\
50 & 2.0 & 1.5 & 75 & 13.26 \\
60 & 3.5 & 3.0 & 70 & 15.80 \\
60 & 3.5 & 1.5 & 60 & 18.17 \\
60 & 2.0 & 3.0 & 40 & 21.74 \\
60 & 2.0 & 1.5 & 36 & 21.27 \\
\hline
\end{tabular}

Table 1 shows the diffusivity of water and the drying time to reach a moisture content of 0.10 $\mathrm{kg}_{\mathrm{w}} / \mathrm{kg}_{\mathrm{dm}}$. Drying temperature followed by the solid loading and the air flow and the air temperature-solid loading interaction are statistically significant $(\mathrm{p}<0.05)$ on drying time. The drying time in trays with longitudinal flow, ${ }^{[3]}$ is three times less than with flow through in packed bed. The air temperature is significant $(p<0.05)$ on effective diffusivity. The air flow and the solid loading affect the diffusivity value, however, its effects are less than the temperature.

3.3. Antioxidant compounds. The content of phenolic compounds, flavonoids and antioxidant capacity are shown in table 2 . The antioxidant capacity of dryed stevia leaves is similar with the fresh leaves. The content of phenols and flavonoids is higher in dry leaves than in fresh stevia leaves, however, the drying conditions studied did not have a significant effect. The solid loading could give a difference in antioxidant compound. The increase in polyphenols may be due to the breakdown of cellular constituents of the material, associated with the availability of precursors of phenolic molecules that are derived from the nonenzymatic interconversion between its. ${ }^{[3,7]}$

3.4. Steviosides compounds. The content of rebaudioside $A\left(R_{A}\right)$ decreases and the content of stevioside $\left(\mathrm{EV}_{\mathrm{V}}\right)$ is increased in dehydrated leaves relative to fresh leaves (Table 3). The degradation of steviol glycosides by hydrolysis has been proposed to explain this behavior ${ }^{[8]}$. A decrease in rebaudioside A may be related to the increase in the content of stevioside. The three variables, temperature, air velocity and charge density, as well as their interactions, 
Effects of drying conditions on the content of glycosides and antioxidants of packed bed of Stevia leaves

have a significant effect $\left(\mathrm{p}<0.05\right.$ ) on the content of $\mathrm{E}_{\mathrm{V}}$ and $\mathrm{R}_{\mathrm{A}}$. Lower flow rate and higher solid loading give a higher content of $\mathrm{R}_{\mathrm{A}}$.

Table 2. Total phenolic compounds, flavonoids and antioxidant capacity of stevia leaves.

\begin{tabular}{|c|c|c|c|c|c|}
\hline $\begin{array}{c}\mathbf{T} \\
{ }^{\circ} \mathrm{C}\end{array}$ & $\begin{array}{c}\overline{\mathbf{u}} \\
\mathrm{m} / \mathrm{s}\end{array}$ & $\begin{array}{c}\boldsymbol{\rho A}_{A} \\
\mathrm{~kg} / \mathrm{m}^{2}\end{array}$ & $\begin{array}{c}\mathbf{F}_{\mathbf{T}} \\
\mathrm{mgGAE} / \mathrm{g}_{\mathrm{dm}}\end{array}$ & $\begin{array}{c}\mathbf{F}_{\mathbf{L}} \\
\mathrm{mgQE} / \mathrm{g}_{\mathrm{dm}}\end{array}$ & $\begin{array}{c}\mathbf{C A}_{\mathbf{A}} \\
\text { \%Inh }\end{array}$ \\
\hline \multicolumn{3}{|c|}{ Fresh } & $71.50 \pm 1.74$ & $161.46 \pm 1.0$ & $92.79 \pm 0.13$ \\
\hline 40 & 2.0 & 1.5 & $91.33 \pm 0.39$ & $135.14 \pm 3.75$ & $91.55 \pm 1.63$ \\
\hline 40 & 2.0 & 3.0 & $114.60 \pm 1.01$ & $275.90 \pm 1.35$ & $92.58 \pm 0.95$ \\
\hline 40 & 3.5 & 1.5 & $95.82 \pm 2.92$ & $126.45 \pm 3.33$ & $92.00 \pm 0.12$ \\
\hline 40 & 3.5 & 3.0 & $118.04 \pm 0.11$ & $373.86 \pm 3.97$ & $93.80 \pm 0.34$ \\
\hline 50 & 2.0 & 1.5 & $115.27 \pm 1.25$ & $342.88 \pm 5.71$ & $91.72 \pm 2.90$ \\
\hline 50 & 2.0 & 3.0 & $118.19 \pm 0.07$ & $319.96 \pm 9.60$ & $93.66 \pm 0.33$ \\
\hline 50 & 3.5 & 1.5 & $81.85 \pm 1.86$ & $100.19 \pm 3.99$ & $92.40 \pm 1.75$ \\
\hline 50 & 3.5 & 3.0 & $102.08 \pm 1.29$ & $264.89 \pm 3.47$ & $92.93 \pm 0.52$ \\
\hline 60 & 2.0 & 1.5 & $91.35 \pm 1.67$ & $259.49 \pm 6.67$ & $93.16 \pm 0.57$ \\
\hline 60 & 2.0 & 3.0 & $94.43 \pm 0.07$ & $308.48 \pm 5.70$ & $92.80 \pm 0.29$ \\
\hline 60 & 3.5 & 1.5 & $83.85 \pm 0.89$ & $276.59 \pm 3.29$ & $92.65 \pm 0.40$ \\
\hline 60 & 3.5 & 3.0 & $114.45 \pm 4.72$ & $402.68 \pm 1.42$ & $93.31 \pm 0.18$ \\
\hline
\end{tabular}

Table 3. Rebaudioside A and stevioside content of stevia deshydrated leaves.

\begin{tabular}{|c|c|c|c|c|}
\hline $\begin{array}{c}\mathbf{T} \\
{ }^{\circ} \mathbf{C} \\
\end{array}$ & $\begin{array}{c}\overline{\mathbf{u}} \\
\mathrm{m} / \mathrm{s}\end{array}$ & $\begin{array}{c}\boldsymbol{\rho}_{A} \\
\mathrm{~kg} / \mathrm{m}^{2}\end{array}$ & $\begin{array}{c}\mathbf{R}_{\mathbf{A}} \\
\mathrm{mg} / \mathrm{g}_{\mathrm{dm}}\end{array}$ & $\begin{array}{c}\mathbf{E v} \\
\mathrm{mg} / \mathrm{g}_{\mathrm{dm}}\end{array}$ \\
\hline & Fresh & & $154.69 \pm 0.13$ & $22.54 \pm 0.08$ \\
\hline 40 & 2.0 & 1.5 & $79.57 \pm 7.96$ & $38.27 \pm 15.01$ \\
\hline 40 & 2.0 & 3.0 & $87.14 \pm 1.82$ & $45.21 \pm 14.08$ \\
\hline 40 & 3.5 & 1.5 & $87.97 \pm 1.84$ & $41.45 \pm 0.19$ \\
\hline 40 & 3.5 & 3.0 & $86.15 \pm 4.72$ & $40.33 \pm 3.79$ \\
\hline 50 & 2.0 & 1.5 & $92.94 \pm 4.43$ & $35.25 \pm 13.02$ \\
\hline 50 & 2.0 & 3.0 & $85.95 \pm 1.12$ & $51.85 \pm 2.28$ \\
\hline 50 & 3.5 & 1.5 & $77.42 \pm 11.51$ & $36.13 \pm 9.34$ \\
\hline 50 & 3.5 & 3.0 & $86.72 \pm 5.75$ & $40.78 \pm 1.39$ \\
\hline 60 & 2.0 & 1.5 & $81.81 \pm 0.32$ & $30.67 \pm 10.84$ \\
\hline 60 & 2.0 & 3.0 & $88.91 \pm 0.87$ & $43.07 \pm 19.67$ \\
\hline 60 & 3.5 & 1.5 & $82.80 \pm 4.64$ & $38.94 \pm 10.70$ \\
\hline 60 & 3.5 & 3.0 & $83.68 \pm 5.46$ & $44.02 \pm 6.02$ \\
\hline
\end{tabular}




\section{Conclusions}

The three variables evaluated (temperature, air flow and solid loading) had a significant effect on the drying time. The order of importance was the temperature, the solid loading and the flow rate.

The drying in packed bed increases the content of phenols and flavonoids of stevia leaves, none of the variables studied was significant in the content of antioxidants, however, the solid loading is a factor that must be taken into consideration; the higher the solid loading, the higher the antioxidant content.

The drying in packed bed reduce the content of rebaudioside $A\left(R_{A}\right)$ and increases the content of stevioside (EV) of stevia leaves. The load of solids was a significant factor, the higher solid loading, the higher content of steviosides.

The proposed drying conditions for the conservation of the physicochemical properties in packed bed of the stevia leaves are $50^{\circ} \mathrm{C}, 2 \mathrm{~m} / \mathrm{s}$ and $1.5 \mathrm{~kg} / \mathrm{m}^{2}$

\section{References}

[1] Wölwer-Rieck, U. The leaves of Stevia rebaudiana (Bertoni), their constituents and the analyses thereof: A review. Journal of Agricultural and Food Chemistry 2012, 60(4), 886-895.

[2] Periche, A.; Castelló, M. L.; Heredia, A.; Escriche, I. (2015). Influence of drying method on steviol glycosides and antioxidants in Stevia rebaudiana leaves. Food Chemistry 2015, 172, 1-6.

[3] Lemus-Mondaca, R.; Ah-Hen, K.; Vega-Gálvez, A.; Honores, C.; Moraga, N. Stevia rebaudiana Leaves: Effect of Drying Process Temperature on Bioactive Components, Antioxidant Capacity and Natural Sweeteners. Plant Foods for Human Nutrition 2016, 71(1), 49-56.

[4] Gasmalla, M.; Yang, R.; Amadou, I.; Hua, X. Nutritional Composition of Stevia rebaudiana Bertoni leaf: effect of drying method. Tropical Journal of Pharmaceutical Research 2014, 13(1), 61.

[5] AOAC Official Methods of Analysis of the association of official analytical chemists. Arlingtong, Virginia, 1984.

[6] Méndez-Lagunas L.L.; Rodríguez-Ramírez J.; Cruz-Gracida M.; Sandoval-Torres S.; Barriada-Bernal G. Convective drying kinetics of strawberry (Fragaria ananassa): effect on antioxidant activity, anthocyanins and total phenolic content. Food Chemistry 2017, 230, 174-181.

[7] Shukla, S.; Mehta, A.; Mehta, P.; Bajpai, V.K. Antioxidant ability and total phenolic content of aqueous leaf extract of Stevia rebaudiana Bert. Experimental and Toxicologic Pathology 2012, 64(7-8), 807-811.

[8] Jooken, E.; Amery, R.; Struyf, T.; Duquenne, B.; Geuns, J.; Meesschaert, B. Stability of Steviol Glycosides in Several Food Matrices. Journal of Agricultural and Food Chemistry 201260 (42), 10606-10612. 